\title{
FLUOROQUINOLONE RESISTANCE PATTERN AMONG THE PATHOGENS CAUSING URINARY TRACT INFECTION IN A TERTIARY CARE HOSPITAL IN KANCHIPURAM DISTRICT, TAMIL NADU, INDIA
}

\author{
SHANTHI BANUKUMAR*, KANNAN I, SUKUMAR RG
}

Department of Microbiology, Tagore Medical College and Hospital, Tamil Nadu Dr MGR Medical University, Rathinamangalam, Chennai - 600127, Tamil Nadu, India. Email: shanthibanukumar@gmail.com

Received: 13 June 2017, Revised and Accepted: 31 July 2017

\section{ABSTRACT}

Objective: The aim is to study the fluoroquinolone resistance pattern among the pathogens causing urinary tract infection (UTI).

Methods: This study was done during January to July 2016 in Tagore Medical College including both hospitalized and out patients. During this 7-month study, around 2695 urine samples were analyzed for the evidence of UTI. 718 samples were culture positive. 366 samples showed fluoroquinolones resistance (50.9\%). They were screened for all fluoroquinolone drugs by doing antimicrobial susceptibility testing by Kirby-Bauer disc diffusion method as per the Clinical and Laboratory Standards Institute CLSI guidelines.

Results: The resistance pattern of different isolates to norfloxacin is Klebsiella pneumoniae - 20\%, Escherichia coli - 51.4\%, Enterococci - 11.1\%, Proteus mirabilis - 50\%, and Staphylococcus saprophyticus - 37.5\%; For nalidixic acid is K pneumoniae - 25\%, E. coli - 6.8\%, Pseudomonas aeruginosa - 71.4\%, Enterococci - 11.1\%, P. mirabilis - 25\%, and S. saprophyticus - 25\%; For ciprofloxacin is K. pneumoniae - 5\%, E. coli - 5.4\%, P. mirabilis - 25\%, and S. saprophyticus - 25\%; and For ofloxacin is K. pneumoniae - 10\%, E. coli - 5.4\%, Enterococci $11.1 \%$, and S. saprophyticus $62.5 \%$.

Conclusion: Due to increasing resistance to fluoroquinolones in many hospitals and to make the developing resistance rates under control, empirical usage of it is either abandoned or should be restricted.

Keywords: Fluoroquinolones, Urinary tract infection, Antimicrobial resistance.

(c) 2017 The Authors. Published by Innovare Academic Sciences Pvt Ltd. This is an open access article under the CC BY license (http://creativecommons. org/licenses/by/4. 0/) DOI: http://dx.doi.org/10.22159/ajpcr.2017.v10i11.20678

\section{INTRODUCTION}

Urinary tract infection (UTI) is the most common bacterial infections caused by wide range of pathogens which is encountered affecting 150 million people worldwide [1]. It is a severe public health problem affecting the economic burden of the country. UTI is of two types. First is uncomplicated one typically affecting otherwise healthy individual involving women, children, and elderly patients [2]. The second is complicated UTI occurring in patients with indwelling catheters, UTI abnormalities, and immunosuppression either drug-induced or physiological or exposure to antibiotics [3].

The UTI plays a major role in causing morbidity in infant boys, older men, and women of all ages. It leads to serious complications such as recurrences, pyelonephritis with sepsis, renal damage in young children, preterm birth, and complications caused by frequent antimicrobial use, such as high-level antibiotic resistance and Clostridium difficile colitis. The indiscriminate use of antibiotics against these uropathogens is the main reason for the emergence and spread of resistance against the antibiotics used $[4,5]$. Now, it has become a worldwide problem affecting all the people around the globe and initiating them to fight against this menace [6].

Fluoroquinolones were used by clinicians to treat the UTI because of very less chances of emergence of drug resistance due to the low minimum inhibitory concentrations against most organisms [7]. They have assumed an important role in treating UTI since they have lesser side effects and also can be given orally. These drugs have a broad spectrum of activity to Gram-positive and in particular to Gram-negative infections [8]. Fluoroquinolones are bactericidal and rapidly acting against Gram-negative bacilli in vitro [9]. Nalidixic acid, the first quinolones used has a narrow influence spectrum with high resistance rates. Even though resistance to nalidixic acid has less clinical importance given to its infrequent use in the treatment of infections, it serves as a marker of the future increase in resistance to fluoroquinolones which has happened with Escherichia coli.

Mechanism of fluoroquinolone resistance is decrease in binding target quinolones to enzymes because of change in DNA gyrase enzyme and/ or the topoisomerase enzyme (s). Mutations can occur in gyrA and parC genes [10]. Second mechanism is decrease in the amount of quinolones entering the cells because of defective function of porin channels [11]. The third mechanism is the various efflux system localized in the membranes of many bacteria which pump the drug out of the bacteria.

Higher rates of resistance to quinolones have been reported from other parts of the world [12]. About $60 \%$ of E. coli strains isolated from hospital-acquired infections in Beijing were resistant to ciprofloxacin [13]. Resistance has become a problem when the usage of quinolones was needed to treat other infections caused by organisms such as gonococcus, salmonella, shigella, or campylobacter $[14,15]$. The initiation of antimicrobial therapy in UTI is empirical, and the knowledge about the antimicrobial resistance pattern among common uropathogens is essential to the clinicians. This can facilitate appropriate and cost-effective therapy to be instituted in a hospital environment. By this, we can achieve both a favorable clinical outcome and a reduction in microbial resistance in health-care institutions [16].

\section{METHODS}

The present study is a cross-sectional study and was conducted in Tagore Medical College and Hospital, a tertiary care hospital at 
Kanchipuram district for 7 months from January 2016 to July 2016. A total of 2695 urine samples were collected from patients suspected to have UTI from both inpatient and outpatient departments.

\section{Ethical committee clearance}

Before the study, it was presented to the Institutional Ethical committee of Tagore Medical College, Chennai, and clearance obtained.

\section{Sample collection and diagnostic procedure}

The mid-stream urine samples collected in a sterile container from the outpatient and inpatient departments of hospital were sent to microbiology diagnostic laboratory. The samples were subjected to gram stain, and the relevant samples were taken for culture and sensitivity. Under strict aseptic precautions, each sample was streaked in respective culture plates such as MacConkey agar, blood agar, and nutrient agar. They were subjected to incubation aerobically for $24 \mathrm{hrs}$ at $37^{\circ} \mathrm{C}$. A total of 718 isolates were culture positive. Culture was positive for various pathogens such as E. coli, Klebsiella pneumoniae, Pseudomonas aeruginosa, Proteus mirabilis, Enterococcus, and Staphylococcus saprophyticus. All these organisms were identified after performing relevant biochemical tests and other confirmatory tests [17]. Their sensitivity was determined using Kirby-Bauer's standard disc diffusion method with Mueller-Hinton agar. Zones were determined by the Clinical and Laboratory Standards Institute guidelines. For quality control, each pathogen's ATCC strains were used as standard, and susceptibility was analyzed for each drug.

Those samples which showed different resistant patterns were selected, and fluoroquinolones-resistant strains were alone taken for the study.

\section{RESULTS}

Among 2695 urine samples, 718 patients showed culture positive. A total of 366 (50.9\%) bacteria isolated were fluoroquinolone resistant.

Table 1: Fluoroquinolone-resistant bacteria isolated from UTI patients

\begin{tabular}{lll}
\hline S. No. & Bacteria isolated & $\begin{array}{l}\text { Total number of } \\
\text { isolates (n=366) (\%) }\end{array}$ \\
\hline 1. & Escherichia coli & $222(61)$ \\
2. & Klebsiella pneumonia & $60(16)$ \\
3. & Pseudomonas aeruginosa & $21(6)$ \\
4. & Proteus mirabilis & $12(3)$ \\
5. & Enterococcus & $27(7.4)$ \\
6. & Staphylococcus saprophyticus & $24(6.6)$ \\
\hline UTI: Urinary tract infection
\end{tabular}

A total of six fluoroquinolone-resistant bacteria species were isolated (Table 1). E. coli is the predominant bacterium (61\%) followed by K. pneumonia. $86 \%$ of the bacteria were Gram-negative bacilli and $14 \%$ of them were Gram-positive cocci.

Table 2 shows the number of different fluoroquinolone-resistant isolates collected from January to July and their distribution pattern.

Table 3 shows the resistance pattern of the bacteria isolated. The present study revealed that ofloxacin resistance in $K$. pneumoniae $(10 \%)$ is more when compared to E. coli and other Gram-negative bacilli. Among the Gram-positive organisms, S. saprophyticus showed more percentage of resistance $(62.5 \%)$ followed by enterococcus (11.1\%) [18]. When compared to the Gram-negative bacilli, Grampositive bacteria showed more resistance to ofloxacin drug among the uropathogens isolated here.

Nalidixic acid resistance is more in $P$. aeruginosa (71.4\%). The resistance pattern of ciprofloxacin is more in P. mirablis $25 \%$ when compared to other Gram-negative bacilli. Among Gram-positive bacteria, S. saprophyticus showed $25 \%$ resistant which is higher compared to other Gram-positive bacteria. Norfloxacin resistance is more in E. coli (51.4\%), and no resistance pattern was observed in P. aeruginosa.

Highest percentage of resistance is noted in $S$. saprophyticus to ofloxacin (62.5\%), P. aeruginosa to nalidixic acid (71.4\%), P. mirabilis to ciprofloxacin (25\%), and S. saprophyticus to norfloxacin (51\%).

\section{DISCUSSION}

The usage of norfloxacin and nalidixic acid should be brought under control to prevent development of resistant pattern among the uropathogens in a health-care institution.

Over the years, the uropathogens show a variable fluoroquinolones susceptibility patterns that are based on factors such as changing patient population and extensive use and misuse of antimicrobial agents [19]. This indirectly relates to local practices of antimicrobial prescriptions. According to surveillance, the resistance to fluoroquinolones ranked as one of the four of the highest priority. Among the critically important drugs used against the microbes [20], they have a very important role in the treatment of more severe life-threatening infections such as septicemia. National data from the five World Health Organization [20] regions showed at least $50 \%$ resistance to fluoroquinolones in $E$. coli. In the present study, the resistance rate of $E$. coli to fluoroquinolones is higher (51.4\%) among the uropathogens isolated.

Table 2: Month wise fluoroquinolone-resistant bacteria isolated from patients

\begin{tabular}{|c|c|c|c|c|c|c|c|c|}
\hline Organism & January & February & March & April & May & June & July & Total \\
\hline Escherichia coli & 18 & 36 & 48 & 33 & 27 & 6 & 54 & 222 \\
\hline Klebsiella & - & 6 & 12 & 15 & 15 & 3 & 9 & 60 \\
\hline Pseudomonas aeruginosa & - & 9 & 9 & - & - & - & 3 & 21 \\
\hline Enterococci & - & 3 & 9 & 3 & 6 & 3 & 3 & 27 \\
\hline Proteus mirabilis & - & - & - & 3 & 3 & 0 & 6 & 12 \\
\hline Staphylococcus saprophyticus & - & - & - & - & 6 & 6 & 12 & 24 \\
\hline
\end{tabular}

Table 3: Resistance pattern of the bacteria isolated for various quinolones

\begin{tabular}{|c|c|c|c|c|c|c|}
\hline Antibiotic & $\begin{array}{l}\text { Klebsiella } \\
\text { pneumonia }(\mathrm{N}=60)\end{array}$ & $\begin{array}{l}\text { Escherichia } \\
\text { coli }(\mathrm{N}=222)\end{array}$ & $\begin{array}{l}\text { Pseudomonas } \\
\text { aeruginosa }(\mathrm{N}=21)\end{array}$ & Enterococci (N=27) & $\begin{array}{l}\text { Proteus } \\
\text { mirabilis }(\mathrm{N}=12)\end{array}$ & $\begin{array}{l}\text { Staphylococcus } \\
\text { saprophyticus }(\mathrm{N}=24)\end{array}$ \\
\hline Ofloxacin & $6(10 \%)$ & $12(5.4 \%)$ & 0 & $3(11.1 \%)$ & 0 & $15(62.5 \%)$ \\
\hline Nalidixic acid & $15(25 \%)$ & $15(6.8 \%)$ & $15(71.4 \%)$ & $3(11.1 \%)$ & $3(25 \%)$ & $6(25 \%)$ \\
\hline Ciprofloxacin & $3(5 \%)$ & $12(5.4 \%)$ & 0 & 0 & $3(25 \%)$ & $6(25 \%)$ \\
\hline Norfloxacin & $12(20 \%)$ & $114(51.4 \%)$ & 0 & $1(11.1 \%)$ & $6(50 \%)$ & $9(37.5 \%)$ \\
\hline
\end{tabular}




\section{CONCLUSIONS}

The study reports indicate that the resistance to fluoroquinolones by the uropathogens differs in different organisms. Henceforth, restriction of their usage in appropriate bacterial infections and reservation of their prescription for important life-threatening infections will reduce emergence and spread of resistance strains within a health-care setup. This helps in maintaining an antimicrobial policy according to the resistant pattern observed in the laboratory-based surveillance studies. A periodically revised antibiotic stewardship in a health-care hospital is mandatory to maintain a good health-care system.

\section{REFERENCES}

1. Stamm WE, Norrby SR. Urinary tract infections: Disease panorama and challenges. J Infect Dis 2001;183 Suppl 1:S1-4.

2. Hooton TM. Uncomplicated urinary tract infection. N Engl J Med 2012;366:1028-37

3. Lichtenberger $\mathrm{P}$, Hooton TM. Complicated urinary tract infections. Curr Infect Dis Rep 2008;10(6):499-504.

4. Sanjay WM, Ghorpade MV, Shivali VG, Annapurna GS, Rashmi MK. A study of vancomycin resistant enterococci isolated from urinary tract infections. Int J Pharm Pharm 2015;7(5):337-9.

5. Carmeli Y, Troillet N, Eliopoulos GM, Samore MH. Emergence of anti-biotic resistant Pseudomonas aeruginosa: Comparision of risks associated with with different anti-pseudomonal agents. Antimicrob Agents Chemother 1999;43(6):1379-82.

6. Kiffer CR, Camargo EC, Shimakura SE, Ribeiro PJ Jr, Bailey TC, Pignatari AC, et al. A spatial approach for the epidemiology of antibiotic use and resistance in community-based studies: The emergence of urban clusters of Escherichia coli quinolone resistance in Sao Paulo, Brasil. Int J Health Geogr 2011;10:17.

7. Lautenbach E, Fishman NO, Biker WB, Castigloni A, Metlay JP, Edelstein $\mathrm{PH}$, et al. Risk factors for fluoroquinolones resistance in nosocomial Escherichia coli and Klebsiella pneumoniae infections. Arch Intern Med 2002;162(21):2469-77.

8. Dholakia N, Rolston KV, Ho DH, LeBlanc B, Bodey GP. Susceptibilities of bacterial isolates from patients with cancer to levofloxacin and other quinolones. Antimicrob Agents Chemother 1994;38(4):848-52.

9. Swiatlo E, Moore E, Watt J, McDaniel LS. In vitro activity of four quinolones against clinical isolates of Pseudomonas aeruginosa determined by E test. Inf J Antimicrob Agents 2000;15:73-6.

10. Hooper DC. Quinolones. In: Mandell G, Bennett J, Dolin R, editors. Mandell, Douglas, and Bennett's Principles and Practice of Infectious Diseases. $5^{\text {th }}$ ed. Philadelphia, PA: Churchill Livingstone; 2000. p. 404-13.

11. Basavaraj CM, Jyothi P. Antibiotic sensitivity pattern of Citrobacter spp. Isolated from patients with urinary tract infections in tertiary care hospital in south India. Int J Pharm Pharm 2015;7(1):252-4.

12. Wenzel RP, Sahm DF, Thornsberry C, Draghi DC, Jones ME, Kailousky JA. In vitro susceptibilities of gram negative Bacteria isolated from hospitalized patients in four European countries, Canada and the U.S in 2000-2001 to expanded spectrum of cephlosporins and comparator antimicrobials: Implications for therapy. Antimicrob Agents Chemother 2003;47:3089-98.

13. Wang H, Dzink-Fox JL, Chen M, Levy SB. Genetic characterization of highly fluoroquinolone resistant clinical $E$. coli strains from china: Role of acrR mutations. Antimicrob Agents Chemother 2001;45:1515-21.

14. Neaman LM, Wang SA, Ohye RG, O'Connor N, Lee MV, Weinstock HS. The epidemiology of fluoroquinolone resistant Neisseria gonorhoeae in Hawaii, 2001. Clin Infect Dis 2004;13:649-54.

15. Low DE, Hooper DC, Rubinstein E. Quinolone resistance and its clinical relevance. Quinolone Antimicrobial Agents. $3^{\text {rd }}$ ed. Washington DC: American Society for Microbial Press; 2003. p. 355-86.

16. Usluer G, Ozgunes I, Leblebicioglu H, Turkish Antibiotic Utilization Study Group. A multicenter point-prevalence study: Antimicrobial prescription frequencies in hospitalized patients in Turkey. Ann Clin Microbiol Antimicrob 2005;4:16.

17. Farmer JJ, Kelly MT. Enterobacteriaceae. In: Lenette EH, Balows A, Hausler WJ, Shadomy HJ, editors. Manual of Clinical Microbiology. Washington DC: American Society for Microbiology; 1991. p. 360-83.

18. National Committee for Clinical Laboratory Standards. Performance Standards for Antimicrobial Disk Susceptibility Tests. Approved Standard M2 A6 (M100-S7). Wagne, PA: NCCLS; 1997.

19. World Health Organization Advisory Group on Integrated Surveillance of Antimicrobial Resistance. Critically Important Antimicrobials of Human Medicine. $3^{\text {rd }}$ Revision; 2012. Available from: http//www.apps. who.int/iris/bitstream/10665/77376/1/9789241504485/eng.pdf.

20. World Health Organization. Antimicrobial Resistance: Global Report on Surveillance; 2014. Available from: http://www.who.int/ drugresistance/documents/surveillancereport/en. 